특집논문-11-16-3-04

\author{
부분 휘도 변화에 강인한 영상 촬영 기반 콘텐츠 검색 방법 \\ 이 주 영 $)^{\ddagger}$, 김 연 희 ${ }^{a)}$, 남 제 호 ${ }^{a)}$
}

\title{
A Content Retrieval Method Using Pictures Taken from a Display Robust to Partial Luminance Change
}

\author{
Jooyoung Lee ${ }^{\text {a) }}$, Younhee Kim ${ }^{\text {a)}}$, and Jeho Nam ${ }^{\text {a) }}$ \\ 요 약
}

논문에서는 디스플레이 촬영 영상을 기반으로 하는 콘텐츠 검색 방법을 제안한다. 본 논문에서 제안한 알고리즘은 조명 등의 촬영 조건 변화에 영향을 최소화하기 위해 인접 블록 간 휘도의 증감 방향을 표현하는 이진 맵을 이용한다. 또한 본 논문에서 구현한 콘텐 츠 검색 시스템은 제안 알고리즘의 효율성을 높이기 위해 스칼라 값을 이용한 인덱스 기반의 2 단계 검색을 수행한다. 알고리즘 비교 실험을 통해 제안 알고리즘에 대한 검증을 수행하고 제안 알고리즘을 이용하여 구현한 콘텐츠 검색 시스템을 기술한다.

\begin{abstract}
In this paper, we propose a content retrieval system using pictures taken from a display for more intelligent mobile services. We focus on the search robustness by minimizing the influence of photographing conditions such as changes in the illumination intensity. For an efficient search and precise detection, as well as robustness, we use a two-step comparison method based on indexing features and a binary map based on luminance and chrominance difference with the adjacent blocks. We also evaluate the proposed algorithm by comparing with the existing algorithms, and we show the content retrieval system that we've implemented using the proposed algorithm.
\end{abstract}

Keyword : image retrieval, image matching, content retrieval, content identification, image copy detection

\section{I. 서 론}

스마트폰의 등장 이후 스마트폰 시장은 급격히 확대되었 고, 카메라, 전화, 풀브라우징, GPS, 진동 센서 등 다양한 기능이 단일 모바일 플랫폼 위에 융합됨에 따라 기존에 없

a) 한국전자통신연구원 방통융합미디어연구부

Broadcast \& Telecommunications Media Research Department, ETRI

\# 교신저자 : 이주영(leejy1003@etri.re.kr)

※ 본 연구는 방송통신위원회의 "지상파 양안식 DTV 방송시스템 기술개발 및 표준햐" 원천기술개발사업의 연구결과로 수행되었음(KCA-2011-10912-02001)

· 접수일(2011년3월17일), 수정일(2011년5월17일),게재확정일(2011년5월17일)
었던 새로운 서비스들이 빠른 속도로 등장하고 있다. 예로 현재 많은 스마트폰은 카메라, 네트워크, GPS 기반의 증강 현실 서비스(예: "Layer"[1]) 및 촬영영상 기반의 검색 서비스 (예:"Google Goggles""2])와 같은 새로운 서비스를 제공하고 있다. 사용자는 이와 같은 서비스를 통해 상점, 음식점, 건물, 명소, 도로, 서적, 음반 등 사용자 주변에 대한 다양한 정보 를 빠르게 획득할 수 있으며, 나아가 다수의 융복합 서비스 들은 사용자의 검색과정을 최소화함으로써 “사용자가 보는 것"에 대한 부가정보를 더욱 쉽고 빠르게 제공하고 있다. 상 기 명시한 서비스와 더불어 본 논문에서 구현한 콘텐츠 부가 
정보 검색시스템은 사용자가 시청 중인 콘텐츠의 시청화면 을 이용하여 해당 콘텐츠의 부가정보를 검색하는 서비스를 제공한다. 이는 사용자의 시청화면을 가리지 않으면서 콘텐 츠에 대한 부가 정보를 제공할 수 있고, 영상 촬영을 통해 검색을 수행하므로 주 디스플레이 기기와 콘텐츠 검색기기 간의 인터페이스 구현 부담이 적다는 이점이 있다.

본 논문에서는 촬영 영상을 이용한 콘텐츠 검색 알고리즘 을 제안하고 해당 알고리즘을 이용한 영상 촬영 기반 콘텐 츠 검색 시스템을 구현한다. 본 논문에서 제안한 알고리즘 은 조명 등의 촬영 조건 변화에 영향을 최소화하기 위해 인 접 블록 간 휘도의 증감 방향을 표현하는 이진 맵을 이용한 다. 더불어 제안 알고리즘의 효율성을 높이기 위해 블록 별 상대적 휘도 평균값을 데이터베이스 인덱스로 이용하여 시 스템 최적화를 수행한다. 알고리즘 비교 실험을 통해 제안 알고리즘에 대한 검증을 수행하고 제안 알고리즘을 이용하 여 구현한 콘텐츠 검색 시스템을 기술한다. 본 논문의 구성 은 다음과 같다. 2장에서는 연구 배경을 서술하고, 3 장에서 는 제안 알고리즘 방식을 기술한 후, 4장에서는 제안 알고리 즘과 기존 알고리즘의 성능 비교 실험을 수행한다. 5 장에서 는 시스템에 제안 알고리즘을 더 효율적으로 적용하기 위한 최적화 과정을 기술하고 6 장에서는 구현한 콘텐츠 부가정 보 제공 시스템을 기술한 후 7장에서 결론을 맺는다.

\section{II. 연구 배경}

\section{1. 관련 연구}

이미지 복사본 검출을 위한 기술 연구는 다양한 방식으 로 진행되어왔으며 크게 이미지 색 정보를 이용하는 방법 ${ }^{[3,13]}$, 모양을 이용하는 방법 ${ }^{[4,7]}$, 색정보와 공간 정보를 함께 이용하는 방법 ${ }^{[5,6,8]}$ 등이 연구되었다.

$\mathrm{Swain}^{[3]}$ 은에서는 객체 식별을 위해 컬러히스토그램 정보 를 사용하였다. 컬러 히스토그램은 이미지 내 객체의 이동 이나 회전에 강인한 특성에 따라 객체 식별에 널리 사용되 고 있으나, 이미지 내 색의 분포를 활용하지 않기 때문에 변별력이 작고 색의 변화에 강인하지 못하므로 동일 이미
지 검색에는 적합하지 않다. $\mathrm{Hsu}^{[13]}$ 는 색의 공간 정보를 활 용하기 위해 이미지를 분할하고 각 서브이미지의 로컬 히 스토그램을 이용하여 이미지 복사본을 검출하는 방법을 제 안하였다. 그러나 제안 기술은 연산량이 많고 색의 변화에 강인하지 못한 단점이 있다. Hampapur ${ }^{[4]}$ 와 Joly ${ }^{[7]}$ 는 각각 윤곽선과 모서리 특징점을 이용한 이미지 비교를 수행하였 다. 그러나 모양 정보는 색 정보에 비해 해상도 변화, 대비

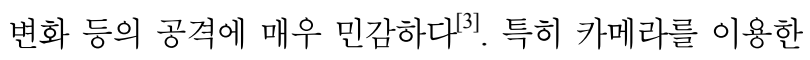
촬영이미지에 대한 콘텐츠 식별의 경우, 조명이나 촬영 기 기의 특성에 따라 알고리즘을 통해 검출하는 모양 정보가 민감하게 변할 수 있으므로 적용하기 어렵다. Bhat ${ }^{[5]}$ 는 블 록 별 휘도 순위를 이용한 이미지 간 유사도를 계산하였다. 전체적 휘도 변화, 해상도 변경, 색상 변경 등을 포함한 다 양한 변화에도 이미지 내 블록의 휘도 순서가 바뀌지 않는 특성을 활용하였다. $\mathrm{Kim}^{[6]}$ 은 $\mathrm{Bhat}^{[5]}$ 와 같이 이미지를 블록 에 대한 평균 휘도를 이용하였다. 그러나 $\mathrm{Kim}^{[6]}$ 은 블록 평 균 휘도를 DCT 변환한 후, 변환 계수의 $\mathrm{AC}$ 성분에 대한 순위를 이용하여 유사도를 계산하며 영상 좌우 반전, 상하 반전 등의 공격에 대해 $\mathrm{Bhat}^{[5]}$ 보다 강인함을 보인다.

$\mathrm{Hsiao}^{[8]}$ 에서는 예상되는 변형 이미지에 대한 특징 정보 를 $\mathrm{Kim}^{[6]}$ 의 방법으로 미리 추출하고, 원본 영상에 대한 특 징 정보와 변형 영상에 대한 특징 정보를 하나의 그룹으로 묶어 $\mathrm{GMM}$ (Gaussian Mixture Model)이나 SVM(Support Vector Model)을 통해 분류하는 기술을 제안하였다. 그러 나 이는 모든 공격에 대한 예측이 힘들고, SVM의 경우 검 출시간이 오래 걸리므로 대용량 이미지 검색에 적합하지 않다.

동영상 필터링 분야에서는 주로 이미지 복사본 검출 기 술과는 달리 시 · 공간적인 특징정보를 동시에 이용한다 ${ }^{[14]}$. 이는 동영상의 고유한 시간정보를 이용하여 복사본 검출 정확도를 향상시킬 수 있으나, 본 논문에서 제안하는 단일 이미지 기반의 복사본 검출 및 검색 기술로 사용하기에는 적합하지 않다.

\section{2. 연구 동기}

Ordinal 방식 ${ }^{[5]}$ 과 DCT Ordinal 방식 ${ }^{[6]}$ 은 이미지의 휘도 
와 화면 내 분포 정보를 이용하여 우수한 이미지 복사본 검출 능력을 보이며, 해상도 변화, 리사이즈, 가로세로 비율 변화, 휘도 변화, 채도 변화, 대비 변화, 색조 변화, 노이즈, 블러 등의 다양한 이미지 변형에 대해서도 강인성을 가진 다. Ordinal 방식에서는 이미지를 $m \times n$ 블록으로 나눈 후 각 블록의 평균 휘도 값을 구하고, 블록 평균 휘도 값의 순 위를 이용하여 두 이미지 간의 유사도를 계산한다. DCT Ordinal 방식에서는 Ordinal 방식에서 이용한 블록 평균 휘 도 값에 DCT 변환을 수행한 뒤, $\mathrm{AC}$ 성분 절대 값의 순위를 이용하여 두 이미지 간의 유사도를 계산한다. 두 알고리즘 모두 다양한 공격에 대한 상당히 강인하나, 화면 내 부분적 인 휘도 변화가 발생할 경우 유사도 계산에 이용하는 블록 순위 정보가 바뀔 우려가 있다. 예를 들어 그림 1은 국지적 인 휘도값 변화에 따른 이미지 블록 간 휘도의 상관관계를 나타낸 것이다. 그림 1-(a)의 상단 이미지는 원본 이미지이 며, 하단 이미지는 좌측 상단에 조명을 가정하여 휘도 값을 부분적으로 변화시킨 이미지이다. 그림 1-(b)는 각 이미지 를 $3 \times 3$ 으로 분할하고 각 블록 별 평균 휘도값과 블록 휘도 순위를 나타낸 것으로 상단(원본 이미지)의 블록 휘도 순위 와 하단(부분 휘도 변경 이미지)의 블록 휘도 순위가 서로 다름을 볼 수 있다. 좌측 상단 블록의 휘도 순위가 상승함과
동시에 좌하단과 하단 블록의 순위가 하락하였으며, 이는 블록 휘도 순위를 이용한 방법이 이미지 전체 변형에는 강 인성을 보이나 부분적인 변형에는 취약함을 의미한다. 또 한 그림 1-(c)와 같이 상기 문제는 DCT Ordinal 방식에서도 나타난다.

영화 포스터나 앨범 쟈켓, 잡지 광고 등을 촬영할 때, 이 미지의 휘도가 부분적으로 변하는 경우는 조명 등의 영향 으로 인해 매우 빈번히 일어난다. 촬영 대상이 모니터, TV 와 같은 디스플레이인 경우, 조명 뿐만 아니라 시야각 등의 원인으로 부분적 휘도 변화는 더욱 심각해진다. 이를 해결 하기 위해 기존 Ordinal/DCT Ordinal 방식이 가진 다양한 변형에 대한 강인성을 유지하면서 부분적인 휘도 변화에도 강인한 이미지 유사도 계산 방식이 필요하다.

본 논문에서는 상기 문제를 해결하기 위해 인접 블록 간 휘도 값의 증감 방향 정보를 이용한다. Ordinal이나 DCT Ordinal 방식과 같이 이미지를 $m \times n$ 으로 분할한 뒤 각 블록의 휘도값과 인접한 블록의 휘도값을 비교하여 휘도값 크기의 증감 여부를 ' 1 ' 또는 ' 0 '로 기록하고, 두 이미지 간 의 유사도를 계산하기 위해서 각 이미지의 인접 블록 간 휘도 증감 정보를 비교한다. 이 경우 조명에 따라 이미지 휘도 변화가 부분적으로 일어나더라도 단일 블록이 아닌
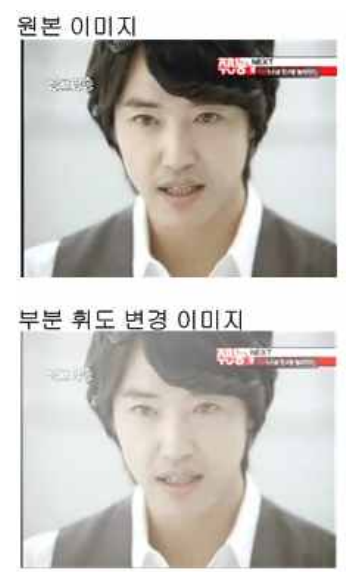

(a) 샘플 이미지

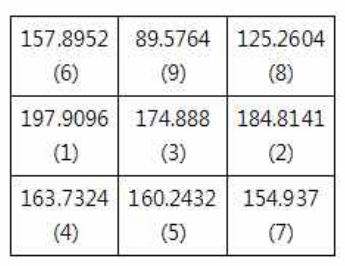

\begin{tabular}{|c|c|c|}
\hline $\begin{array}{c}196.6392 \\
(4)\end{array}$ & $\begin{array}{c}154.7849 \\
(9)\end{array}$ & $\begin{array}{c}166.755 \\
(8)\end{array}$ \\
\hline $\begin{array}{c}215.236 \\
(1)\end{array}$ & $\begin{array}{c}198.1102 \\
(3)\end{array}$ & $\begin{array}{c}200.8437 \\
(2)\end{array}$ \\
\hline $\begin{array}{c}183.5992 \\
(5)\end{array}$ & $\begin{array}{c}178.7358 \\
(6)\end{array}$ & $\begin{array}{c}167.7197 \\
(7)\end{array}$ \\
\hline
\end{tabular}

(b) $3 \times 3$ 블록 별 평균 휘도 및 순위

\begin{tabular}{|c|c|c|}
\hline 299.9549 & $\begin{array}{c}245.2051 \\
(2)\end{array}$ & $\begin{array}{c}268.4745 \\
(1)\end{array}$ \\
\hline $\begin{array}{c}4.1275 \\
(8)\end{array}$ & $\begin{array}{c}49.9689 \\
(3)\end{array}$ & $\begin{array}{c}20.9845 \\
(7)\end{array}$ \\
\hline $\begin{array}{c}30.2886 \\
(6)\end{array}$ & $\begin{array}{c}40.807 \\
(4)\end{array}$ & $\begin{array}{c}36.51 \\
(5)\end{array}$ \\
\hline
\end{tabular}

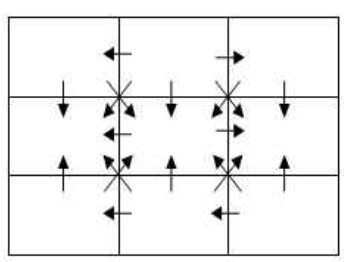

\begin{tabular}{|c|c|c|}
\hline 343.7973 & $\begin{array}{c}306.9372 \\
(2)\end{array}$ & $\begin{array}{c}309.0662 \\
(1)\end{array}$ \\
\hline $\begin{array}{c}9.2207 \\
(7)\end{array}$ & $\begin{array}{c}16.9358 \\
(6)\end{array}$ & $\begin{array}{c}0.6821 \\
(8)\end{array}$ \\
\hline $\begin{array}{c}20.5077 \\
(5)\end{array}$ & $\begin{array}{c}25.597 \\
(4)\end{array}$ & $\begin{array}{c}27.4395 \\
(3)\end{array}$ \\
\hline
\end{tabular}

(c) $3 \times 3$ 블록 별 평균 휘도 DCT 변환 절대값 및 $\mathbf{A C}$ 성분 순위

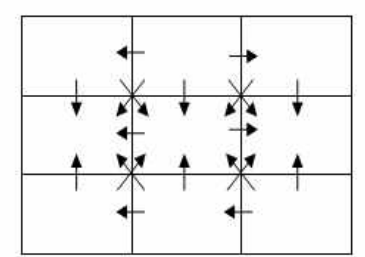

(d) 인접 블록 간 휘도 증가 방향

그림 1. 부분 휘도 변화에 따른 블록 간 휘도 관계 분석

Fig. 1. Analysis of the luminance correlation between the image sub-blocks according to partial change in luminance 
다수의 인접한 블록에 걸쳐 조명의 영향을 받으므로 인접 블록 간 휘도값 증감 방향은 변하지 않을 가능성이 높다. 예로 그림 1-(d)는 그림 1-(a)의 원본 이미지와 국지적인 휘 도 변화 이미지에 대한 인접 블록 간 휘도 증감 방향을 나타 낸다. 블록 간의 화살표 방향은 휘도 값이 낮은 방향에서 높은 방향으로 향하며 그림 상에서 보이듯이 원본 이미지 의 인접 블록 간의 휘도 증감 방향과 조명 영향을 받은 이미 지의 인접 블록 간 휘도 증감 방향은 동일하다.

\section{III. 블록 휘도 기반 유사도 계산 방법}

\section{1. 이미지 특징정보 추출}

제안 알고리즘은 이미지의 특징정보를 추출하기 위해 인
접 블록 간 휘도의 증감 여부를 이진 정보로 추출한다. 인접 블록 간 휘도 크기 비교는 수평 방향의 인접 블록, 수직 방 향의 인접블록, 대각선 방향의 인접블록을 대상으로 한다. 인접 블록의 휘도 증감 정보를 일련의 비트열로 표현하기 위해 수평방향, 수직방향, 대각선 방향 순으로 휘도 증감 여부를 체크하고 인접 블록 간 비교 결과에 각각 $1 \mathrm{bit}$ 씩을 할당한다. 즉, 휘도가 증가하거나 같을 경우 1 을 할당하고 휘도가 감소할 경우 0 를 할당한다. 그림 2 는 이미지 블록을 $4 \times 4$ 로 분할할 경우의 인접 블록 간 휘도 증감 여부의 확 인 순서를 나타낸다. 전체 이미지 상의 확인 순서는 숫자로 표시하였다. 그림 상에서 화살표의 시작 블록은 기준블록 을 의미하며, 화살표의 끝 블록은 비교 대상 블록을 의미한 다. 기준 블록보다 비교 대상 블록의 휘도가 높거나 같으면 1 을 기록하며, 낮을 경우 0 을 기록한다. $4 \times 4$ 이미지의 경 우 인접블록 간 휘도 증감 여부를 표현하기 위해 42 비트가

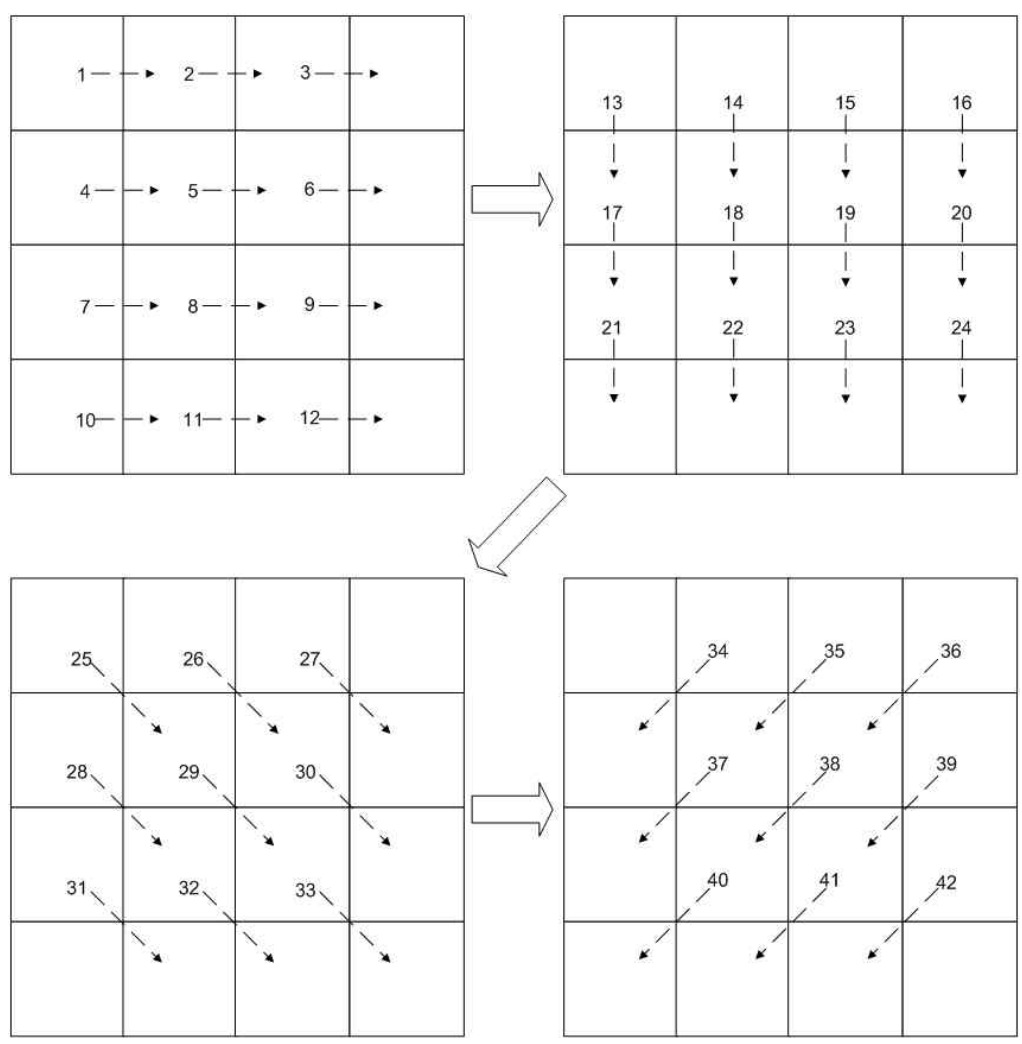

그림 2. $4 \times 4$ 이미지의 인접 블록 간 휘도 증감 여부 확인 순서

Fig. 2. Checking order of luminance difference between adjacent blocks in a $4 \times 4$ image 
필요하다. $m \times n$ 으로 분할한 이미지를 이용하는 경우 필 요한 비트 수는 $4 m n-3(m+n)+2$ 비트이며, 본 논문 에서는 인접 블록 간 휘도 증감 정보를 표현한 비트열을 $\mathrm{D}-\mathrm{map}$ 으로 정의한다.

\section{2. 이미지 간 유사도 계산}

두 이미지 간의 유사도 계산은 각 이미지의 D-map 정보 를 이용하여 계산하며, 이는 식 (1)과 같이 두 D-map 비트 열의 XOR 연산을 기반으로 비교적 간단히 이루어진다. 식 (1)에서 $D M_{Q}$ 는 쿼리 이미지의 D-map 정보이고, $D M_{T}$ 는 테스트 이미지의 D-map 정보이다. 두 이미지 간의 거리 $D$ 는 $D M_{Q}$ 와 $D M_{T}$ 간의 $\mathrm{XOR}$ 연산 벡터결과 $X$ 에 존재하 는 ' 1 '의 개수를 이용한다. 즉 두 이미지 간의 거리 $D$ 는 인접 블록 휘도 중 증감방향이 일치하지 않는 수를 의미한 다. 반면 두 이미지 간 유사도 $S$ 는 인접 블록 휘도 중 증감 방향이 일치하는 비율을 나타낸다. 식 (1)에서 $\mathrm{N}$ 은 $m \times n$ 블록 이미지의 D-map 사이즈를 의미한다.

$$
\begin{aligned}
& S=1-D / N \\
& D=\sum_{i=1}^{N}\left(X_{i}\right) \\
& X=D M_{Q} \oplus D M_{T} \\
& N=4 m n-3(m+n)+2
\end{aligned}
$$

\section{IV. 실험 및 검증}

본 논문에서는 제안 알고리즘의 우수성을 검증하기 위해 Ordinal 방식 및 DCT Ordinal 방식과 제안 알고리즘의 비 교 실험을 수행하였다. 각 알고리즘의 콘텐츠 검출 실험을
위해 형광등 조명 아래에서 스마트폰을 이용하여 촬영한 디스플레이 영상을 이용하였다.

\section{표 1. 실험 환경}

Table 1. Experimental environment

\begin{tabular}{|c|c|}
\hline 항목 & 내용 \\
\hline 데이터베이스 & MySQL Server 5.1 \\
\hline 샘플 콘텐츠 & 15초 광고 2198개 \\
\hline 초당 15프레임, 320 × 240 해새앙도)
\end{tabular}

\section{1. 디스플레이 촬영 이미지 검출 실험}

스마트폰을 이용하여 촬영한 디스플레이 이미지의 콘텐 츠 검출 실험은 표1과 같이 2,202건의 광고 콘텐츠(전체 49,3785 프레임)를 대상으로 쿼리 이미지를 입력하고 해당 쿼리 이미지에 해당하는 광고 콘텐츠를 올바르게 검출하는 비율을 산출하였다. 광고 콘텐츠는 초당 15 프레임의 15 초 분량의 동영상이며, 형광등 조명 아래에서 24 인치 LCD 모 니터를 통해 재생 중인 광고 콘텐츠를 스마트폰을 이용하 여 촬영하고 이를 크롭하는 방식으로 쿼리이미지 200장을 획득하였다. 그림 3 은 쿼리 이미지 샘플을 보이며 색상, 채 도, 대비, 전체 휘도 변화와 더불어 부분적인 휘도 변화가 이루어졌음을 확인할 수 있다. 실험은 제안 알고리즘, Ordinal, DCT Ordinal 등 세 가지 알고리즘에 대해 $5 \times 5$, $6 \times 6,7 \times 7,8 \times 8,9 \times 9$ 분할 방식을 이용한 실험 결과를 측 정하였다. 각 실험은 200 개의 동일한 쿼리 이미지 입력에 대한 결과를 측정하였고, 각 쿼리 이미지에 해당하는 올바
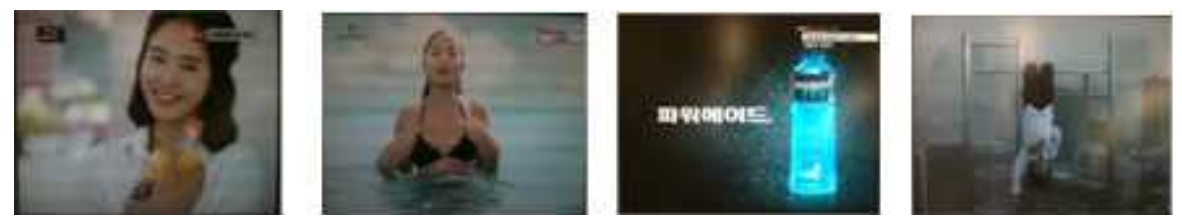

그림 3. 쿼리 이미지 샘플

Fig. 3. Samples of query images 


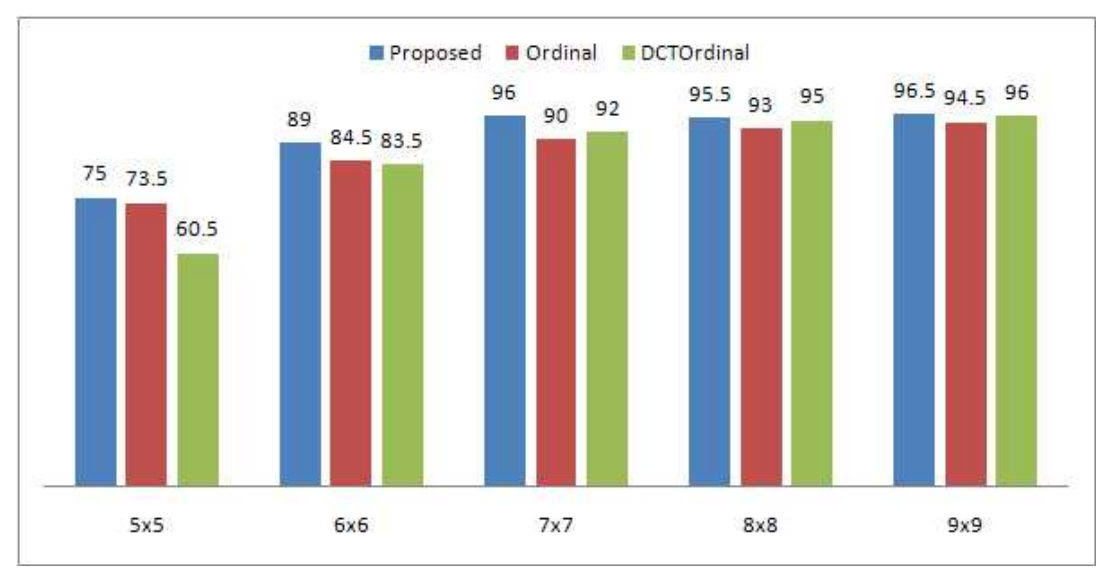

그림 4. 비교 대상 알고리즘 콘텐츠 검출 결과(\%)

Fig. 4. Content retrieval result of the algorithms in comparison

른 콘텐츠가 유사도 순위 3 위 안에 포함될 경우 성공으로 간주하였고, 그 외의 경우 실패로 간주하였다. 이는 본 논문 에서 구현한 시스템이 촬영 콘텐츠에 대한 부가 정보를 제 공하는 시스템으로 사용자에게 3 개의 후보 콘텐츠를 제안 하는 것은 서비스 레벨에서 지극히 정상적이며, 더불어 2198 개의 광고 콘텐츠 중 같은 샷을 포함하는 시리즈 광고 가 상당수 포함되어있기 때문이다. 그림 4는 제안 알고리즘 과 Ordinal, DCT Ordinal 방식의 블록 수에 따른 콘텐츠 검출률을 나타낸다. 그림 4에서 보이듯이 각 알고리즘은 전 반적으로 블록 수가 증가할수록 콘텐츠 검출률이 높아지며, 블록 수 전 구간에 걸쳐 제안 알고리즘이 Ordinal, DCT Ordinal 방식에 비해 다소간 정확한 검출을 수행하고 있다. 특히 적은 블록 수를 이용하는 경우 제안 알고리즘이 기타 알고리즘에 비해 더욱 우수한 검출률을 보인다.

\section{2. 특징정보 사이즈 및 검출 속도 비교 실험}

제안 알고리즘은 이미지 특징정보를 비트열 형태로 저장 하기 때문에 기존 알고리즘에 비해 특징정보 사이즈가 작 다. $m \times n$ 블록을 이용한 경우 제안 알고리즘의 한 이미지 당 특징정보 사이즈는 $4 m n-3(m+n)+2$ 비트이며, Ordinal 방식과 DCT Ordinal방식은 블록 휘도 순위를 8bit 로 가정하였을 경우 특징정보 사이즈가 $m \times n \times 8$ 비트이
다. 그림 5 는 블록 사이즈 별로 제안 알고리즘과 비교 알고 리즘의 이미지 특징정보 사이즈를 나타낸 것이며, 제안 알 고리즘의 특징정보 사이즈가 비교 알고리즘에 비해 월등히 작음을 보인다.

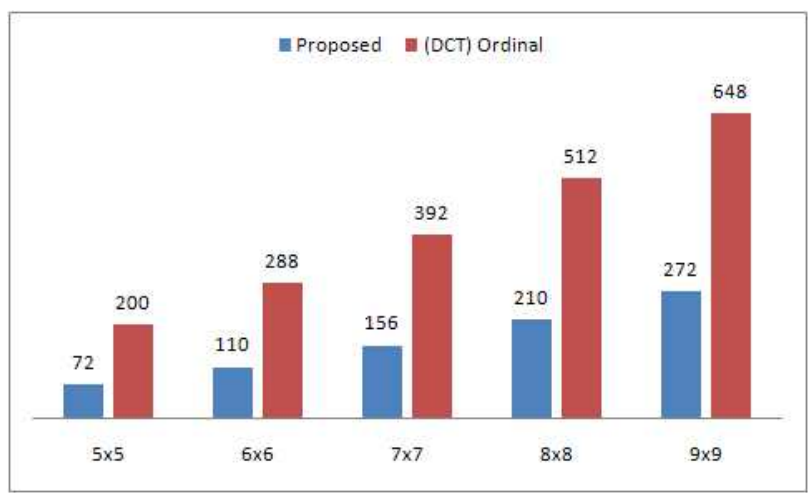

그림 5. 알고리즘 별 특징정보 사이즈(bit)

Fig. 5. Feature size of the algorithms

또한 제안 알고리즘은 비트열 연산을 통해 이미지 간 거 리를 계산에 필요한 연산량을 대폭 줄였다. 제안 알고리즘 은 비트열 특징정보 간 XOR 연산과 ' 1 ' 비트 카운팅을 통 해 이미지 간 거리를 계산하는 반면, 비교 알고리즘은 블록 별 휘도 순위의 차를 구하고 이를 합산하는 과정을 거친다. 그림 6 은 제안 알고리즘과 비교 알고리즘의 블록 사이즈 


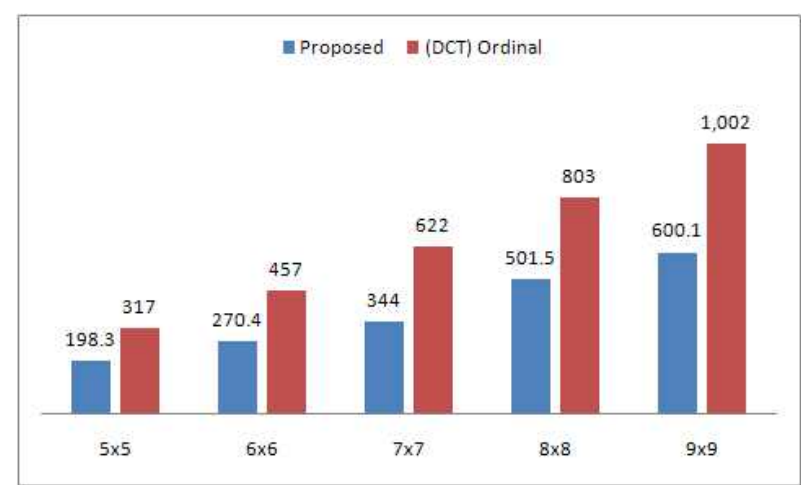

그림 6. 알고리즘 별 특징정보 거리 계산 시간(ms)

Fig. 6. Elapsed time of the algorithms for feature distance calculation

별 특징정보 거리 계산 시간을 계산한 것이다. 검출 소요 시간은 $2.4 \mathrm{GHz}$ 듀얼코어 $\mathrm{PC}$ 에서 49,785 회의 이미지 간 거 리 계산에 소요되는 시간을 10 회 측정 후 평균값을 구한 것이며, 메모리 로딩 및 순위 정렬 등에 소요되는 시간은 배제하였다.

\section{V. 검색 시스템 최적화}

본 논문에서 제안한 알고리즘은 비트열을 이용한 특징정 보를 사용함으로써 기존 방식의 알고리즘에 비해 더욱 빠 른 이미지 매칭을 수행한다. 그러나 데이터베이스에 저장 된 이미지가 방대해질 경우를 대비하여 아래와 같이 스칼 라 타입의 특징정보를 데이터베이스 인덱스로 사용함으로 써 이미지 검색속도를 더욱 빠르게 할 수 있다. 즉 그림 7과 같이 제안 알고리즘을 이용한 이미지 특징정보 비교에 앞 서 데이터베이스 인덱스가 되는 특징정보 값을 이용하여 소수의 후보 이미지를 미리 추출함으로써 콘텐츠 검출 속 도를 증가시킬 수 있다.

\section{1. 인덱스 특징정보 선택}

데이터베이스의 인덱스로 사용할 스칼라 타입의 특징정 보를 선택하기 위해 본 논문에서는 원영상과 촬영영상의 대비(Contrast), 복잡도, DCT(Discrete Cosine Transform) 계수, 블록 휘도값 등 다양한 이미지 특징정보를 추출하여 분석하였으며, 특징 정보의 분포가 넓고 원영상과 촬영 영 상 간의 오차가 적은 특징 정보를 선별하였다.

비교 대상이 된 특징정보 중, 이미지의 대비는 이미지를 표현하는 가장 직관적인 특징정보 중 하나이다. 이미지 대 비에 대한 정의는 유일하지 않기 때문에 여러 문헌에서 다 양한 형태의 대비를 계산하는 방식이 이용되고 있으나, 본 논문에서는 두 이미지를 비교하기 위해 자주 이용되는 RMS(root-mean-square) 대비 ${ }^{[9]}$ 를 이용하였다. 또한 웨이블 릿 서브밴드 GGD (Generalized Gaussian Distribution)의 shape 변수를 이용한 이미지 복잡도 ${ }^{[10,1]}$ 에 대한 비교도 수 행하였다. 더불어 DCT 계수는 이미지/영상 압축을 위해 널 리 쓰이는 압축 기법으로 DCT 변환을 할 경우 에너지가 저주파 영역으로 집중되는 특성이 있으므로 본 논문에서는 이미지를 $5 \times 5$ 블록으로 분할한 후 평균 휘도에 대한 DCT 변환을 통해 획득한 저주파 영역의 DCT 계수에 대한 비교 실험도 수행하였다. 마지막으로 $5 \times 5$ 이미지 블록의 상대 적인 휘도에 대한 비교도 수행하였다. 여기서 상대적 휘도 란 이미지 전체 휘도 평균에 대한 특정 블록의 휘도 평균의 비율을 의미하며, 연산량이 적고 전체적인 휘도 변화에 강 인한 특징이 있다. 상기 특징 정보 추출 시 촬영환경 영향을 최소화하기 위해 원영상과 촬영 영상의 휘도 분포에 대한 정규화 작업을 선행하였으며 이는 이미지 휘도 범위을 각 각 최대 휘도값에서 최소 휘도값까지 분포하도록 변환하는 과정을 통해 수행하였다. 또한 블록 이미지의 DCT 계수와 이미지 블록의 상대적 휘도값에 대해서는 블록 휘도 레벨

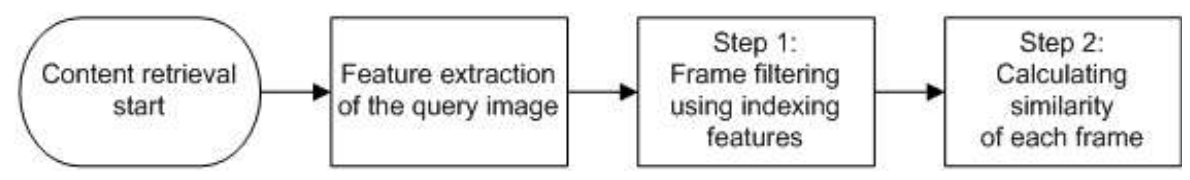

그림 7. 2단계 콘텐츠 검출 순서

Fig. 7. Sequence of two-step content retrieval 


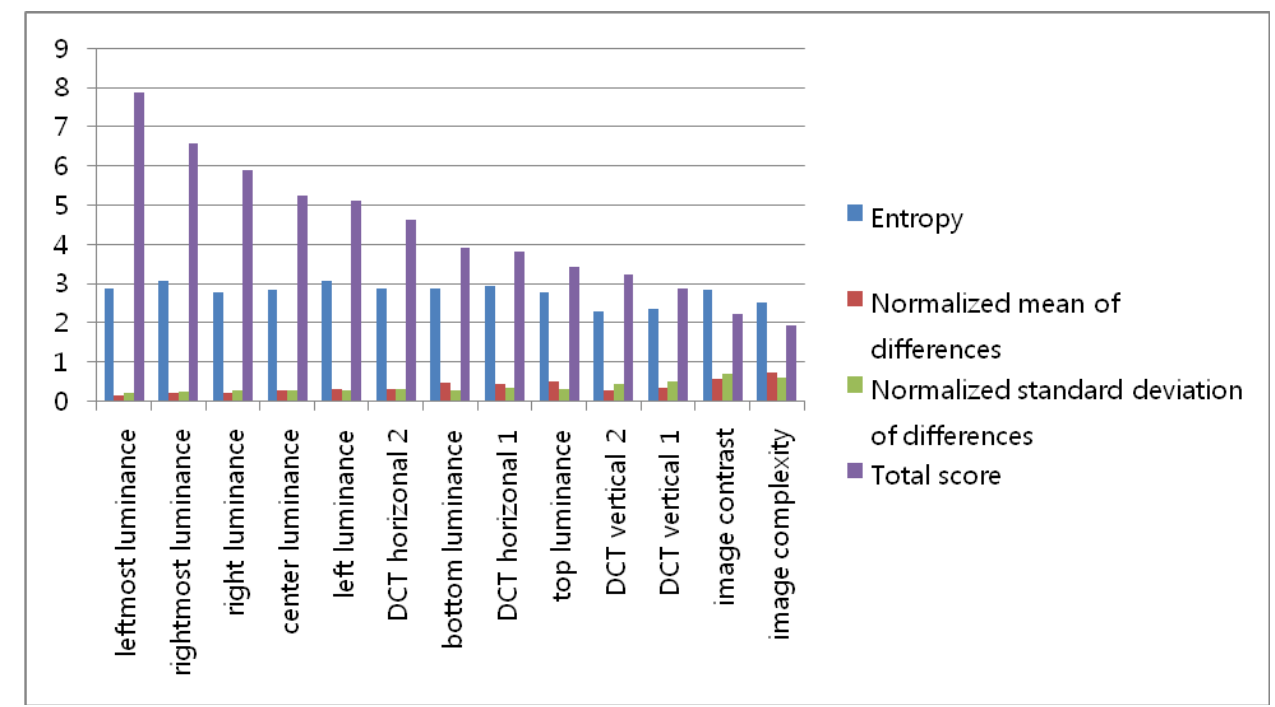

그림 8. 특징정보 비교 차트

Fig. 8. A feature comparison chart

에서 정규화 작업을 수행하였다.

본 논문에서는 특징 정보의 효용성을 산출하기 위해 엔 트로피(entropy), 원영상과 촬영영상에서 추출한 특징 값의 오차 평균, 해당 오차의 표준편차 정보를 세 가지 요인 (factor)으로 이용하였다. 엔트로피는 특징 값이 어느 한 쪽 으로 치우치지 않고 고르게 분포할수록 값이 높아진다 ${ }^{[12]}$. 그러므로 본 연구의 특징정보 선택을 위해서는 높은 엔트 로피 값을 가진 특징정보가 유리하다. 반면 원영상과 촬영 영상에서 추출한 특징 값의 오차 평균과 오차의 표준편차 는 낮을수록 오차율을 줄일 수 있다. 그러나 원영상과 촬영 영상에서 추출한 특징 값의 오차 평균과 오차의 표준편차 는 각 특징정보의 특성에 따라 편차 범위가 상이해질 수 있으므로, 오차 평균과 오차의 표준편차를 각 특징정보의 표준편차 값으로 나눔으로써 특징정보들 간의 상이한 편차 에 대한 정규화를 수행하였다. 각 특징정보의 세 가지 요인 을 산출하기 위해 테스트 이미지 200장과 쿼리 이미지 200 장을이용하였으며, 엔트로피는 테스트 이미지를 이용하여 추출하였고, 원영상과 촬영영상에서 추출한 특징 값의 오 차 평균과 해당 오차의 표준편차 값은 테스트 이미지와 쿼 리 이미지 간의 오차 값을 기반으로 산출하였다. 상기 세 가지 요인을 이용한 특징정보 효용성에 대한 점수 산정 방
법은 식 (2)와 같다. 식 (2)에서 $E$ 는 특징 정보의 엔트로피 이고, $N M D$ 는 정규화된 평균 오차이며, $N S D$ 는 정규화 된 오차의 표준편차이다.

$$
\text { Total Score }=E /(N M D+N S D)
$$

그림 8은 각 특징정보들의 효용성 계산 방법에 따른 비교 차트이며, 상대적 블록 휘도의 효용성이 다른 변환 기반의 특징정보에 비해 높게 나타난다. 그러므로 본 연구에서는 후보 이미지 추출을 위한 필터링 인덱스를 생성하기 위해 다섯 개의 상대적 블록 휘도를 이용한다.

\section{2. 후보 이미지 추출 방법}

후보 이미지 추출은 D-map을 이용한 유사도 계산 시간 을 줄이기 위해 데이터베이스 인덱스가 되는 스칼라 특징 정보 값을 이용하여 특정 유사 범위에 속한 이미지를 먼저 검출하는 과정이다. 본 연구에서는 앞 절에서 분석한 바와 같이 이미지의 상대적 블록 휘도를 이용하여 데이터베이스 인덱스를 구축한다. 즉 시스템은 이미지 등록 시 입력 이미 지에 대한 다섯 블록의 상대적 휘도를 추출하여 이를 인덱 
스로 저장하고, 이미지 검색 시 쿼리 이미지에 대한 블록 별 상대적 휘도를 추출한 후 해당 휘도 값을 기준으로 일정 한 범위에 속한 이미지를 데이터베이스로부터 획득한다. 이후 시스템은 획득한 후보 이미지와 쿼리 이미지의 Dmap을 비교하여 유사도를 계산한다. 즉, 후보 영상 인덱스 의 추출 범위가 $\alpha$ 일 경우, 시스템은 쿼리 영상 내 인덱스 블록들의 상대적 휘도를 추출한 후, 해당 값들을 데이터베 이스에 저장된 이미지의 각 인덱스 컬럼 값들과 비교하여 모든 영역에서의 차이가 $\alpha$ 이내일 경우, 해당 이미지들을 D-map 유사도 비교를 위한 후보 영상으로 획득한다. 후보 영상 추출에 좁은 인덱스 범위를 이용할 경우 D-map을 이 용한 유사도 계산 시간을 크게 줄일 수 있으나 콘텐츠 검출 률이 떨어질 수 있고, 반면 넓은 인덱스 범위를 이용할 경우 콘텐츠 검출률 하락을 방지할 수 있으나, D-map을 이용한 유사도 계산 시간이 증가한다.

그림 9는 후보영상 추출을 위한 인덱스 범위에 따른 제외 영상 비율 및 최종 콘텐츠 검출률을 나타낸다. 테스트에서 후보영상들에 대한 최종 유사도 계산은 $7 \times 7$ 이미지 블록 기반의 제안 알고리즘을 이용하였다. 0.1 에서 0.5 까지의 인
덱스 범위에 따라 테스트를 수행한 결과, 인덱스 범위가 0.3 이상인 경우에는 $95.5 \%$ 의 검출률을 달성하며 전체 이미지 에 대한 유사도 비교 시의 검출률인 $96 \%$ 에 거의 근접하였 고, 0.2 의 경우에는 $89.5 \%$ 로 약간의 검출률 저하가 발생하 였으며, 0.1 의 경우에는 검출률이 상당히 하락하였다. 반면 인덱스 범위를 0.1 로 이용한 경우 후보 영상 추출 단계를 통해 D-map 유사도 비교 대상에서 제외시키는 이미지의 비율이 $99.985 \%$ 였고, 0.2 일 경우 $99.652 \%, 0.3$ 일 경우 $98.212 \%, 0.4$ 일 경우 $94.9 \%, 0.5$ 일 경우 $89.654 \%$ 였다. 본 연구에서 구현한 시스템에서는 검출률에 영향을 최대한 미 치지 않으면서 가능한 소수의 후보 영상을 추출하여 검출 시간을 단축할 수 있는 0.3 을 인덱스 범위로 사용하였다.

\section{VI. 시스템 구현}

본 논문에서는 제안한 알고리즘을 이용하여 디스플레이 촬영 기반 콘텐츠 부가정보 제공 시스템을 구현하였다. 그 림 10 과 같이 콘텐츠 획득 시스템은 콘텐츠 부가정보 획득

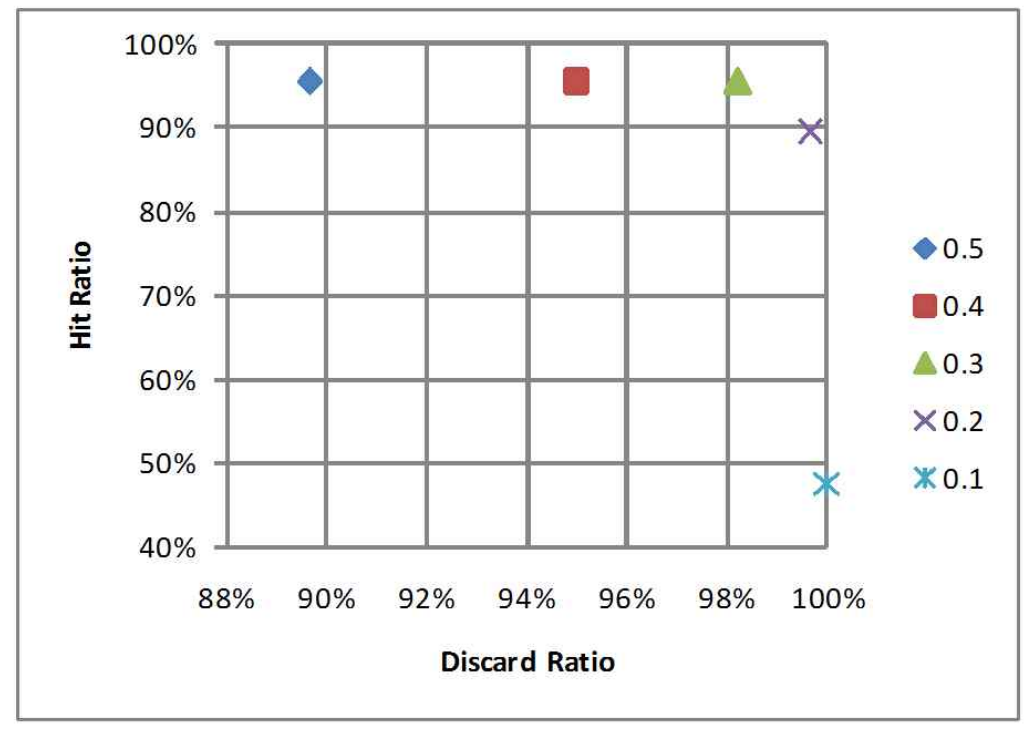

그림 9. 후보영상 추출을 위한 인덱스 범위에 따른 제외 영상 비율 및 최종 콘텐츠 검출률

Fig. 9. The hit ratio and the discard ratio of varying level of the filtering range 


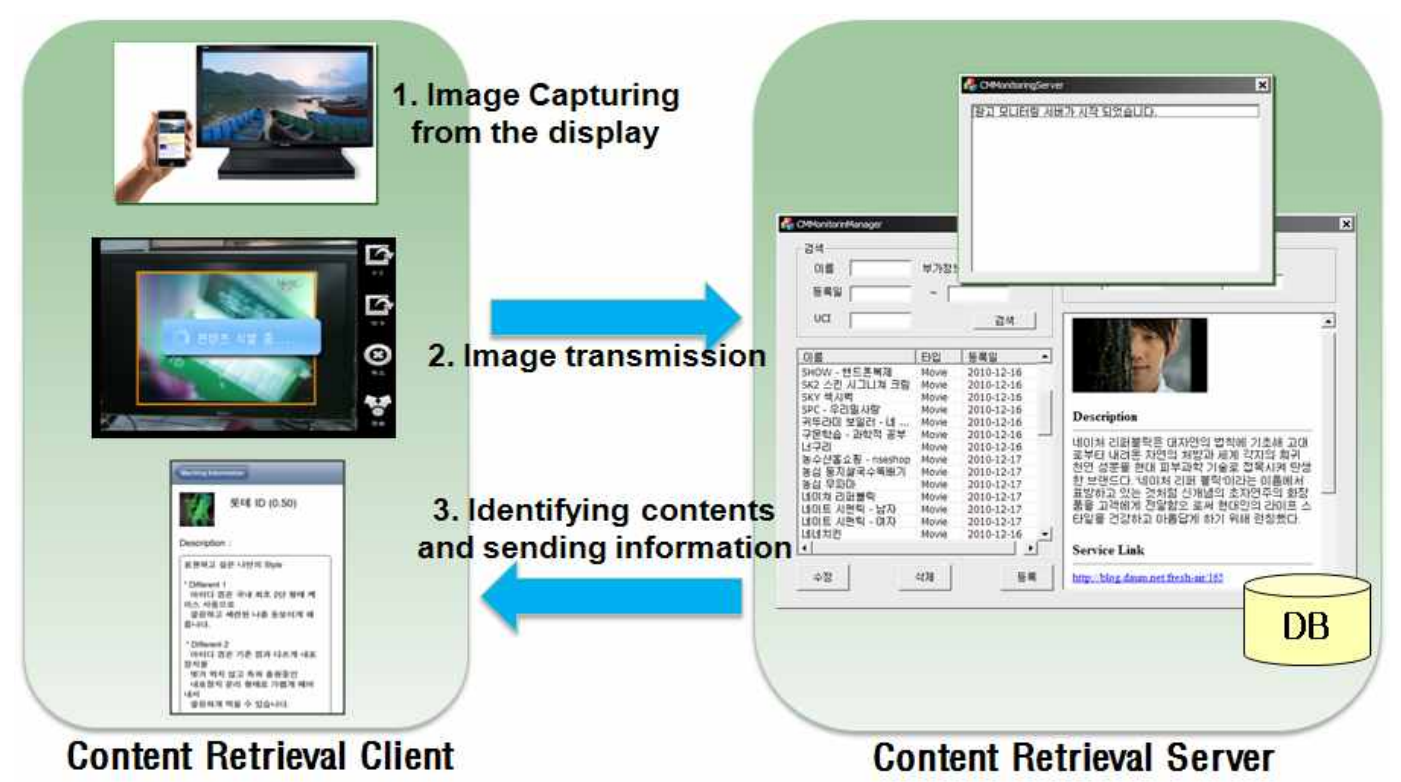

그림 10. 디스플레이 촬영 기반 콘텐츠 부가정보 제공 시스템

Fig. 10. A content information system using pictures taken from a display

서버와 클라이언트로 구성된다. 클라이언트 단말은 디스플 레이의 콘텐츠 영상을 촬영한 후, 촬영 영상을 서버로 전송 하고 서버로부터 콘텐츠 부가정보를 획득하여 이를 사용자 에게 출력한다. 콘텐츠 부가정보 제공서버는 클라이언트로 부터 촬영 이미지를 수신하고, 수신 이미지의 특징정보를 추출하고 추출한 특징정보를 기반으로 미리 저장된 콘텐츠 데이터베이스를 이용하여 촬영 콘텐츠를 식별한 후, 식별 콘텐츠의 부가 정보를 단말로 전송한다. 표 2 는 콘텐츠 획 득 시스템 구축 환경을 보인다.

표 2. 콘텐츠 획득 시스템 구축 환경

Table 2. Implementation environment of content retrieval system

\begin{tabular}{|c|c|}
\hline \multicolumn{2}{|c|}{ 콘텐츠 획득 서버 } \\
\hline OS & Microsoft Windows Server 2008 x64 SP2 Std \\
\hline RAM & 32GB \\
\hline HDD & M00GB x 8 (RAID 0) \\
\hline 데이터베이스 & MySQL Server 5.1.49 \\
\hline 개발 언어 및 환경 & C++, Microsoft Visual Studio 2008 SP2 \\
\hline \hline \multicolumn{2}{|c|}{ 콘텐츠 획득 클라이언트 } \\
\hline 디바이스 & Apple iPhone 3Gs, Samsung Galaxy Tab \\
\hline
\end{tabular}

\section{VII. 결 론}

본 논문에서는 디스플레이 촬영 영상을 기반으로 하는 콘텐츠 식별 알고리즘을 제안하고 해당 알고리즘을 이용한 콘텐츠 식별 시스템을 구축하였다. 본 논문에서 제안한 알 고리즘은 인접 블록 간 휘도의 증감 방향을 표현하는 이진 맵을 이용함으로써 조명 등의 촬영 조건 변화에 영향을 최 소화하였으며 특징정보 저장 및 계산 비용을 최소화하였다. 또한 우수한 이미지 복사본 검출 능력과 다양한 이미지 변 형에 대한 강인성을 갖춘 Ordinal 방식와 DCT Ordinal 방 식과의 비교 실험을 통해 제안 알고리즘의 우수성을 입증 하였다. 제안 알고리즘은 비교 알고리즘들에 비해 높은 콘 텐츠 검출률을 보였으며, 연산 비용 및 저장 비용 측면에서 도 기존 방식에 비해 우수한 결과를 보였다. 특히 적은 수의 블록을 이용할 경우 제안 알고리즘은 비교 알고리즘에 비 해 더욱 우수한 결과를 보였다. 즉 방대한 양의 이미지 프레 임 검색의 경우 제안 알고리즘이 비교 알고리즘에 비해 낮 은 연산량으로 우수한 검출 결과를 얻을 수 있음을 보였다. 또한 본 논문에서는 제안 알고리즘의 효율성을 높이기 위 해 이미지 내 블록의 상대적 휘도 값을 기반으로 하는 인덱 
싱 기법을 이용하여 시스템의 검출 성능을 극대화 하였다. 특히 인덱스 특징정보로 사용하는 블록 평균 휘도의 범위 를 0.3 으로 적용할 경우, $98 \%$ 이상의 프레임을 1 차 필터링 에서 제외함으로써 시스템의 빠른 검색 성능을 보장함과 동시에, 전체 프레임 대상의 검색과 거의 유사한 수준의 검 출 성능을 확보하였다. 나아가 본 논문에서는 제안 알고리 즘 및 최적화 기법을 기반으로 하는 콘텐츠 부가정보 제공 서버와 모바일 클라이언트 단말을 개발함으로써, 제안 알 고리즘 기반의 서비스에 대한 가능성을 검증하였다. 제안 알고리즘은 향후 다양한 촬영 기반의 검색 서비스를 위한 기반 기술로써 활용될 수 있을 것이다.

\section{참 고 문 헌}

[1] Layer, http://www.layar.com/

[2] Google Goggle, http://www.google.com/mobile/goggles/

[3] M.J. Swain and B.H. Ballard, "Color Indexing", Int'l J. Computer Vision, vol. 7, no. 1, pp. 11-32, 1991.

[4] A. Hampapur and R. Bolle, "Feature based indexing for media tracking," Proc. IEEE ICME, vol. 3, pp. 1709-1712, July 2000.

[5] D. N. Bhat and S. K. Nayar, "Ordinal measures for image correspondence,” IEEE Trans. Pattern Anal. Mach. Intell., vol. 20, no. 4, pp.
415.423, Apr. 1998.

[6] C. Kim, “Content-based image copy detection," Signal Process.: Image Commun., vol. 18, pp. 169.184, 2003.

[7] A. Joly, O. Buisson, and C. Frelicot, "Content-based copy retrieval using distortion-based probabilistic similarity search," IEEE Trans. Multimedia, vol. 9, no. 2, Feb. 2007.

[8] J.-H. Hsiao, C.-S. Chen, L.-F. Chien and M.-S. Chen , M. 2007. "A new approach to image copy detection based on extended feature sets." IEEE Trans. Image Process 16, pp. 2069-2079, Aug. 2007

[9] E. Peli, "Contrast in complex images", J. Opt. Soc. Amer. A, vol. 7, no. 10, pp.2032-2040, 1990.

[10] Q. Liu and A.H. Sung, "Feature Mining and Nuero-Fuzzy Inference System for Steganalysis of LSB Matching Steganography in Grayscale Images", Proc. Of 20th International Joint Conference on Artificial Intelligence (IJCAI), 2007, pp.2808-2813.

[11] Q. Liu, A. Sung, B. Ribeiro, M. Wei, Z. Chen and J. Xu, "Image complexity and feature mining for steganalysis of least significant bit matching steganography“, Information Sciences 178 (1), pp. 21 -36, 2008

[12] I. Guyon and A. Elisseeff, "An introduction to variable and feature selection," J. Machine Learning Res. (Special Issue on Variable and Feature Selection), vol. 3, pp. 1157-1182, 2003.

[13] W. Hsu, T. S. Chua, and H. K. Pung, "An integrated color-spatial approach to content-based image retrieval", Proc. ACM Multimedia, pp.305-313, 1995.

[14] 김주섭, 남제호, "DTV 방송프로그램의 온라인 불법전송 차단을 위한 비 디오 복사본 검출 알고리즘", 한국방송공학회논문지, v. 13 , no.5, pp.662-676, 2008

저 자 소 개

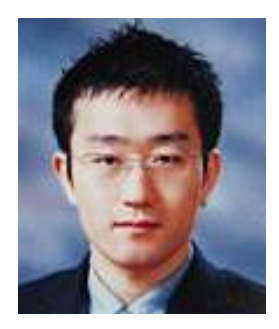

\section{이 주 영}

- 2003년 : 아주대학교 미디어학과 (학사)

- 2006년 : 한국과학기술원 전산학과 (석사)

- 2006년 현재 : 한국전지통신연구원 방통융합미디어연구부

- 주관심분야 : 콘텐츠 저작권 보호기술, 멀티미디어 데이터베이스 검색기술, 모바일 3DTV 기술

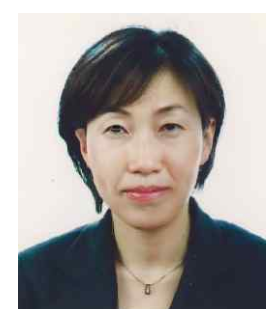

\section{김 연 희}

- 2000년 2월 : 아주대학교 정보및컴퓨터공학과 졸업 (공학사)

- 2002년 2월 : 아주대학교 정보및컴퓨터공학과 졸업 (공학석사)

- 2009년 1월 : George Mason University, Computer Science 졸업 (이학박사)

- 2009년 4월 현재 : 한국전자통신연구원(ETRI) 방통융합미디어연구부 선임연구원

- 주관심분야 : 영상 기반 정보은닉, 콘텐츠 보회유통, 영상신호처리 및 영상압축 
저 자 소 개

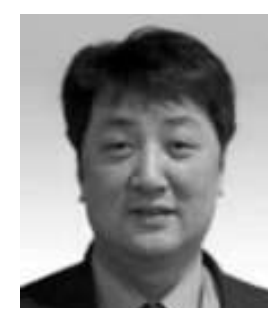

남 제 호

- 1992년 2월 : 홍익대학교 전기제어공학과 학사

- 1996년 12월 : University of Minnesota, Electrical Engineering 석사

- 2000년 12월 : University of Minnesota, Electrical Engineering 박사

- 2001년 2월 현재 : 한국전자통신연구원(ETRI) 방통융합미디어연구부 책임연구원

- 2007년 1월 현재 : 과학기술연합대학원대학교(UST) 이동통신 및 디지털방송공학과 부교수

- 주관심분야 : 멀티미디어 신호처리, 디지털 홀로그래피, 콘텐츠 보회유통, 디지털방송기술, MPEG 